\title{
Increased risk of Alzheimer's disease in mothers who gave birth to children with Down's syndrome before 35 years of age
}

Schupf N, Kapell D, Nightingale B, et al. Specificity of fivefold increase in AD in mothers of adults with Down syndrome. Neurology 2001 Sep 25;57:979-84.

QUESTION: Are mothers who give birth to children with Down's syndrome (DS) before the age of 35 years at increased risk of neurological or medical disorders?

Design

Cohort study.

\section{Setting}

Community based study in the 9 county downstate region of New York, USA.

\section{Participants}

A random sample of parents $(n=395)$ of 200 adults who were 30-70 years of age and had DS, and matched group of parents $(n=495)$ of 252 adults with other forms of mental retardation (control group) were identified from the New York State Office of Mental Retardation and Developmental Disabilities registry.

\section{Assessment of risk factors}

Parents' age at birth of children with DS or other forms of mental retardation and parents' medical history were obtained by interview with parents and other first degree relatives.

\section{Main outcome measures}

Diagnosis of Alzheimer's disease (AD), other dementias, and age related disorders in the parents.

\section{Main results}

Mothers who were $\leqslant 35$ years of age when their children with DS were born were 4-5 times as likely to develop $\mathrm{AD}$ as control mothers (table). The risk of $\mathrm{AD}$ among mothers who were $>35$ years of age when their children with DS were born was not statistically increased (table). Risk of AD among fathers of children with DS was similar to that of the control fathers, and did not vary by age at the child's birth (table). Risk of other dementias and of other age related medical conditions were similar

Risk of Alzheimer's disease $(A D)$ in parents of children with Down's syndrome

\begin{tabular}{ll} 
Risk factor & $\begin{array}{l}\text { Relative risk of AD } \\
(95 \% \mathrm{Cl})\end{array}$ \\
\hline Mothers giving birth at $\leqslant 35$ years & $4.8(2.1$ to 11.2$)$ \\
\hline Mothers giving birth at $>35$ years & $1.8(0.6 \text { to } 5.1)^{*}$ \\
\hline Fathers having a child at $\leqslant 35$ years & $1.0(0.3 \text { to } 3.2)^{*}$ \\
\hline Fathers having a child at $>35$ years & $1.2(0.4 \text { to } 3.4)^{*}$ \\
\hline
\end{tabular}

${ }^{*}$ Not statistically significant among mothers and fathers of children with DS and control parents regardless of age at the child's birth.

\section{Conclusion}

There was an increased risk of Alzheimer's disease in mothers who gave birth to children with Down's syndrome before the age of 35 years.

\section{COMMENTARY}

So does $\mathrm{DS}$ lead to $\mathrm{AD}$, or does a risk factor for $\mathrm{AD}$ in women lead to increased risk of DS? One of the important proteins in $\mathrm{AD}$ pathogenesis is amyloid precursor protein (APP) coded on chromosome $21 .{ }^{1}$ Mutations in this gene lead to early $\mathrm{AD}$, but they are thought to be very rare (only 20 pedigree families known). However, the presence of an extra chromosome 21 in DS leads to a much increased incidence of $\mathrm{AD}$ in this group $(50 \%$ of those who reach $50 \mathrm{y}$ of age). This has been assumed to be due to the extra chromosome causing a 50\% increase in amyloid production, which basically overburdens the clearance system. But 2 other scenarios could now be postulated. Maybe an APP defect exists on chromosome 21 that alone can increase late onset $\mathrm{AD}$ rates in the parent, but is passed on twice when trisomy or translocation occurs, producing higher $\mathrm{AD}$ rates in $\mathrm{DS}$ - by mimicking autosomal dominant transmission. Alternatively an APP defect may interfere with meiosis, increasing the risk of non-disjunction and hence DS. 95\% of DS trisomies are due to maternal non-disjunction, ${ }^{2}$ and although trisomy increases with age, a genetic susceptibility to translocation is believed more common in younger parents, accounting for the difference below 35 years. Obviously, cause and effect cannot be drawn from this well presented data. However, the fact that a genetic and molecular link is known to occur in these disorders, plus this apparent 5-fold increase in $\mathrm{AD}$ incidence in the mothers of DS, suggests new research avenues. Early presenting amyloidopathies of the brain have been proven to be due to several genetic mutations, and this finding in the mothers of DS children implies that their chromosome 21 could hold more clues that may help unlock both these tragic disorders.

Roger Bullock, MA, MBBS

Victoria Hospital Swindon, UK

1 Mills J, Reiner PB. Regulation of amyloid precursor protein cleavage. J Neurochem 1999;72:443-60.

2 Bugge M, Collins A, Petersen MB, et al. Non-dysjunction of chromosome 18. Hum Mol Genetics 1998;7:661-9.
Sources of funding:

Alzheimer's Association and the New York State Office of Mental Retardation and Developmental Disabilities.

For correspondence: Dr N Schupf, New York State Institute for Basic Research, Staten Island, NY, USA.

ns24@columbia.edu

See:Earlier onset and increased risk of Alzheimer's disease in Down's syndrome was associated with sex and apolipoprotein $E$ genotype.

Evidence-Based Mental Health 1998;1:125. 